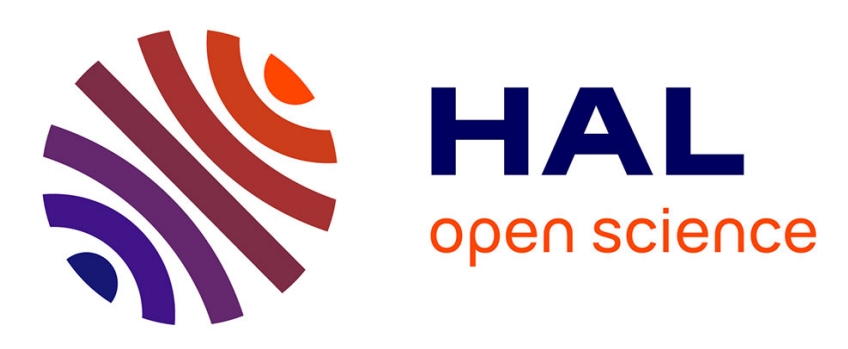

\title{
Kinetic Modeling of the Thermal Destruction of Nitrogen Mustard Gas
}

\author{
Juan-Carlos Lizardo-Huerta, Baptiste Sirjean, Laurent Verdier, René Fournet, \\ Pierre-Alexandre Glaude
}

\section{- To cite this version: \\ Juan-Carlos Lizardo-Huerta, Baptiste Sirjean, Laurent Verdier, René Fournet, Pierre-Alexandre Glaude. Kinetic Modeling of the Thermal Destruction of Nitrogen Mustard Gas. Journal of Physical Chemistry A, 2017, 121 (17), pp.3254-3262. 10.1021/acs.jpca.7b01238 . hal-01708219}

\author{
HAL Id: hal-01708219 \\ https://hal.science/hal-01708219
}

Submitted on 13 Feb 2018

HAL is a multi-disciplinary open access archive for the deposit and dissemination of scientific research documents, whether they are published or not. The documents may come from teaching and research institutions in France or abroad, or from public or private research centers.
L'archive ouverte pluridisciplinaire HAL, est destinée au dépôt et à la diffusion de documents scientifiques de niveau recherche, publiés ou non, émanant des établissements d'enseignement et de recherche français ou étrangers, des laboratoires publics ou privés. 


\title{
Kinetic Modeling of the Thermal Destruction of Nitrogen Mustard Gas
}

\author{
Juan-Carlos Lizardo-Huerta ${ }^{\dagger}$, Baptiste Sirjean ${ }^{\dagger}$, Laurent Verdier ${ }^{\ddagger}$, René Fournet ${ }^{\dagger}$, \\ Pierre-Alexandre Glaude ${ }^{\dagger, *}$ \\ ${ }^{\dagger}$ Laboratoire Réactions et Génie des Procédés, CNRS, Université de Lorraine, \\ 1 rue Grandville BP 2045154001 Nancy Cedex, France \\ ${ }^{\ddagger}$ DGA Maîtrise NRBC, Site du Bouchet, 5 rue Lavoisier, BP $n^{\circ} 3,91710$ Vert le Petit, France \\ *corresponding author: pierre-alexande.glaude@univ-lorraine.fr
}

\begin{abstract}
The destruction of stockpiles or unexploded ammunitions of nitrogen mustard (tris (2chloroethyl) amine, HN-3) requires the development of safe processes. The thermal destruction of this kind of compound is one of the most efficient method of destruction. Because of the high-level of toxicity of this chemical, there is a considerable lack of knowledge on the chemical kinetics of this toxic at high temperatures. In this study, a detailed chemical kinetic model for the pyrolysis of nitrogen mustard gas is developed based on a large number of thermo-kinetic parameters calculated with theoretical chemistry. The thermal decomposition of HN-3 is shown to mainly proceed through stepwise dechlorination making with $\mathrm{Cl}$-atom being the principal chain carrier. The successive losses of chlorine atom mainly lead to unsaturated amines without chlorine groups. Theoretical calculations demonstrated that the thermal decomposition of these compounds ultimately lead to the formation of pyrrole, which can accumulate at low temperature. At higher temperatures, pyrrole yields HCN and acetylene. Simulations also predict that about $52 \%$ of the total flux of decomposition of HN-3 leads to the formation of N,N-diethenyl-2-chloroethylamine (P29) which acts as a chain branching agent because its unimolecular decomposition is preponderant and products one chlorine and one hydrogen atoms. Comparisons with the simulated reactivity of sulfur mustard gas are also performed and show that $\mathrm{HN}-3$ is more reactive that the former toxic. The higher number of chlorine atoms in $\mathrm{HN}-3$ compared to sulfur mustard ( $3 v s .2)$ and the formation of the chain branching intermediate P29 during its decomposition explain this behavior.
\end{abstract}




\section{Introduction and background}

Tris (2-chloroethyl) amine $\left[\left(\mathrm{ClCH}_{2} \mathrm{CH}_{2}\right)_{3}-\mathrm{N}\right]$, also called nitrogen mustard gas or $\mathrm{HN}-3$ is a vesicant with similar effects to those of yperite (bis-(2-chloroethyl) sulfide, also known as mustard gas or HD). HN-3, together with bis-(2-chloroethyl) ethylamine (HN-1) and bis-(2-chloroethyl) methylamine (HN-2) are part of a series of nitrogen blister agents (Figure 1). HN-1 was initially developed in the 1920s for medical purposes, and was found to have blistering effects similar to that of sulfur mustard (yperite) and Lewisite ${ }^{1}$.

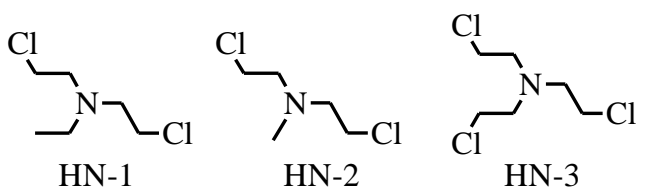

Figure 1. Chemical structures of the nitrogen blister agents.

At room temperature, HN-3 is a colorless, oily liquid. This toxic was produced between 1920 and 1930 as a potential chemical weapon, but was never used for military purposes ${ }^{1,2}$. This toxic is a powerful irritant that damage the skin, eyes and respiratory system and can enter into the body cells and damage the immune system ${ }^{2}$.

The destruction of these stockpiles of chemical warfare agents has received much attention in their technological aspect and one of the safest and efficient methods reported in the literature is to destroy them using thermal treatments ${ }^{3}$. Low temperature treatments such as hydrolysis or dissolution in a solvent for later incineration are efficient but necessitate the removal of the chemical warfare agent from munition ${ }^{4}$. Such methods raise crucial questions regarding the byproducts obtained in the process. The manipulation of such poisonous chemicals is extremely difficult to safely perform experimental works. Therefore, the modeling of their behavior under high-temperature conditions is a method of choice to understand their decomposition chemistry and the pyrolysis products formed. This study positions itself at this level of the effort towards the development of safe thermal processes for the destruction of $\mathrm{HN}-3$ stockpiles.

Previous work available in the literature on the degradation of this molecule essentially involves hydrolysis at low temperature ${ }^{1,3,5}$. This treatment leads to the formation of triethanolamine $\left[\left(\mathrm{HOCH}_{2} \mathrm{CH}_{2}\right)_{3}-\mathrm{N}\right]$. The mechanism involves the formation of an unstable cyclic intermediate that will be attacked by water to form an alcohol and $\mathrm{HCl}$; the same sequence is repeated until the displacement of the three chloride ions by three molecules of water (Scheme 1) ${ }^{6}$. 

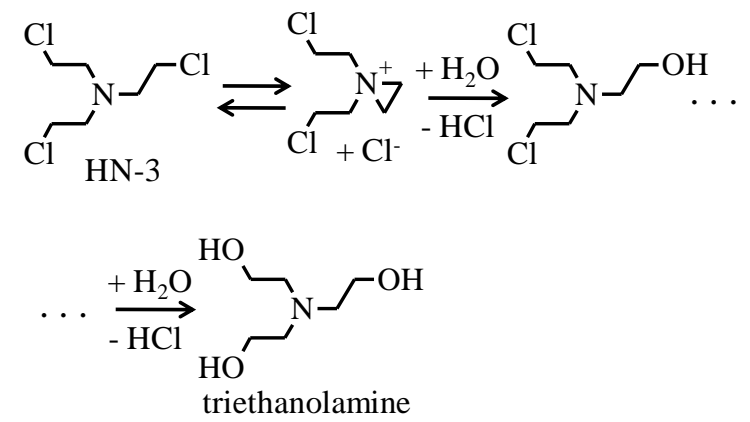

Scheme 1. Mechanism of hydrolysis of $\mathrm{HN}-3^{6}$.

Regarding the thermal degradation of $\mathrm{HN}-3$, we have not identified works available in the literature, either on pyrolysis or oxidation of this molecule. Given the high-level of toxicity of these compounds, it is usual in the field of thermal destruction of chemical warfare to study less toxic simulants. These simulants feature a similar chemical structure in order to simulate the behavior of the target toxic. In the case of $\mathrm{HN}-3$, and based on analogies with sulfur mustard ${ }^{7}$, its simulant would be triethylamine (TEA, $\left.\left[\left(\mathrm{CH}_{3} \mathrm{CH}_{2}\right)_{3}-\mathrm{N}\right]\right)$. The literature on TEA pyrolysis is very scarce. It can be noted that in 1958 Cullis and Waddington ${ }^{8}$ studied the oxidation of TEA at low-temperatures $(\sim 200$ $-400{ }^{\circ} \mathrm{C}$ ). This is the first experimental study that gives insights on the fundamental kinetics occurring for TEA low-temperature combustion. However, the chemistry taking place at these temperatures, with the presence of oxygen, is not similar to the one expected at high temperature (above $\sim 600{ }^{\circ} \mathrm{C}$ ) without oxygen. In 2006, Wang et al. ${ }^{9}$ studied the pyrolysis of triethylamine as an initiator for heptane cracking. They performed pyrolysis of heptane and TEA for individual and mixed chemicals in a tubular flow reactor operating at atmospheric pressure and temperatures ranging from 500 to $700{ }^{\circ} \mathrm{C}$. The pyrolysis products were analyzed using gas chromatography-mass spectrometry methods and ethane, ethylene, methane, propene, and propane were identified as the major gas products, in weight. 1-ethylaziridine, acetonitrile and 1-methylaziridinze were the main nitrogen containing intermediates detected by the authors. Based on their experimental results, they proposed a qualitative chain reaction mechanism to explain their experimental observations. Wang et al. concluded, that under their conditions, the initial C-N bond fission in TEA is preponderant. In a subsequent theoretical study, Wang and Lin $^{10}$ performed theoretical calculations to understand the initiation of triethylamine.

In this study, the bond dissociation energies of TEA were calculated at the B3LYP/6-31G* level of theory (Figure 2). 


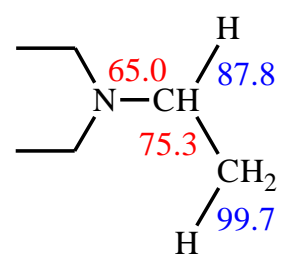

Figure 2. Bond dissociation energies of triethylamine computed at the B3LYP/6-31G* level of theory (in kcal mol ${ }^{-1}$ ) by Wang and $\operatorname{Lin}^{10}$.

From their calculations, it can be seen that the N-C bond breaking, is the most favorable process with a computed bond dissociation energy of $65.0 \mathrm{kcal} \mathrm{mol}^{-1}$. It can be noted that the level of calculation used by these authors (B3LYP/6-31G*) will not lead to accurate absolute values but is expected to be qualitatively correct in terms of relative bond dissociation energies.

They also computed the potential energy surface of two unimolecular decomposition routes of the radical N,N-diethyl $\left[\mathrm{CH}_{3} \mathrm{CH}_{2} \mathrm{~N}(.) \mathrm{CH}_{2} \mathrm{CH}_{3}\right]$ at the MP2/6-31G* level of calculation. From their calculations, they concluded that "N,N-Diethyl is found of the most stable intermediate during the pyrolysis of triethylamine, ...". We disagree with this conclusion as the full picture of the pyrolysis chemistry of any organic compound can only be understood using detailed chemical kinetic models that comprehensively includes the whole chain reaction mechanisms. It is well known that initial bond fissions will create the initial radicals that will start the chain reaction mechanisms that will make the initiations in TEA almost negligible.

The present study aims to develop a detailed chemical kinetic model for the pyrolysis of tris (2chloroethyl) amine based on a large number of theoretical calculations including quantum chemistry, statistical thermodynamic and reaction rate theory.

\section{Computational methods}

In the context of this study, it was found necessary to use calculations from quantum chemistry in order to obtain the high-pressure kinetic constants and thermodynamic data associated with elementary processes involved in the HN-3 thermal decomposition, that are not available in the literature.

The calculations of the electronic structure of the reactants, products and transition states have been computed at CBS-QB3 level of theory. This composite method involves geometry optimization at the B3LYP/CBSB7 level of calculation and energy computations using several levels of theory. A basis set extrapolation allows to estimate a "complete basis set" (CBS) energy ${ }^{11,12}$. In the case of the $\alpha$-scission of the resonance stabilized $\mathrm{CH}_{3} \mathrm{NCHCH}_{2}$ radical to $\mathrm{CH}_{3}=\mathrm{N}$ and $\mathrm{C}_{2} \mathrm{H}_{3}$, it was not possible to optimize a transition state using B3LYP functional, and the level of calculation MP2/6-311+G(d,p) 
was then used for the optimization of the geometry. In addition, an analysis of vibrational frequencies was systematically performed to confirm the nature of the transition states (TS). In the cases where the imaginary frequency is not non-ambiguously related to the reaction coordinate, the Intrinsic Reaction Coordinate (IRC) approach ${ }^{13}$ has been used to ensure the correct connection between a given transition state structure and the reactant and product. In this study all the calculation has been performed using the GAUSSIAN 09 Rev. B.01 software ${ }^{14}$. Accuracy of energy calculations can be estimated to be better than $1 \mathrm{kcal} \mathrm{mol}^{-1}$ for molecules and $2 \mathrm{kcal} \mathrm{mol}^{-1}$ for radicals and transition states $^{11}$.

To obtain accurate values of thermodynamic data $\left(\Delta_{\mathrm{f}} \mathrm{H}^{\circ}{ }_{298}, \mathrm{~S}^{\circ}{ }_{298}, \mathrm{C}_{\mathrm{P},(\mathrm{T})}\right)^{\circ}$ and high-pressure limit rate constants, the low frequency vibration modes, corresponding to the internal rotations, were treated as hindered rotors instead as harmonic oscillators, using THERMROT ${ }^{15}$, an in-house code that allows a 1-DHR treatment of internal rotations and takes into account the coupling of torsional modes using the method proposed by Vansteenkiste et al. ${ }^{16}$. The $1 \times \mathrm{BDE}$ module developed by Miyoshi ${ }^{17}$ is used to compute the eigenvalues for the torsional modes by solving the 1D-Schrödinger equation. 1-DHR treatment was used with torsional potential calculated from relaxed scans computed at B3LYP/6-311G(2d,d,p) level of theory. Quantum tunneling was considered using the Eckart approach for reactions involving $\mathrm{H}$-atom transfers ${ }^{18}$.

\section{Chemical Kinetic Model Development}

The detailed chemical model for the combustion of nitrogen mustard gas was developed based on a classic hierarchical approach. It involves a primary mechanism that includes all the reactions of the target toxic, a comprehensive $\mathrm{C}_{0}-\mathrm{C}_{2}$ reaction basis including the combustion chemistry of small hydrocarbons that has been extended to $\mathrm{C} / \mathrm{H} / \mathrm{N} / \mathrm{Cl}$ molecules and radicals that features less than two heavy atoms. The last part of the mechanism is a secondary mechanism that consists of the decomposition reactions of molecules not taken into account in the reaction basis. Each of the three main parts of the chemical kinetic mechanism are detailed in the following subsections.

\section{Reaction basis}

In the kinetic model of $\mathrm{HN}-3$, the $\mathrm{C}_{0}-\mathrm{C}_{2}$ reaction basis of the EXGAS software (an automatic generator of detailed chemical kinetic model for the combustion of hydrocarbons) was adopted ${ }^{19}$. The reactions of $\mathrm{C}_{3}-\mathrm{C}_{4}$ unsaturated hydrocarbon, leading to the formation of benzene, was appended to the $\mathrm{C}_{0}-\mathrm{C}_{2}$ reaction basis ${ }^{20,21}$. The pyrolysis reactions of $\mathrm{C} / \mathrm{H} / \mathrm{Cl}$ compounds (featuring less than 2 heavy atoms) were taken from the kinetic model developed by Leylegian et al. ${ }^{22}$ which was validated 
again laminar flame structure experiments of $\mathrm{CHxCly}$ compounds. The reactions of nitrogen containing species $(\mathrm{C} / \mathrm{H} / \mathrm{O} / \mathrm{N})$ were included based on the kinetic model proposed by Konnov et al. ${ }^{23}$. Pressure dependent rate constant were included for these light species when available.

\section{Primary mechanism}

In the primary mechanism, all unimolecular decomposition reactions of tris (2-chloroethyl) amine as well as propagations reactions are considered. The molecules formed are, if their small enough (less than two heavy atoms), decomposed in the reaction basis, where their comprehensive decomposition chemistry is present, or have to be consumed in a secondary mechanism that was developed in this work (see below). Most of the reactions have been calculated theoretically, especially in the case of unimolecular reactions or when no reliable structure reactivity relationship was applicable.

\section{Unimolecular reactions}

Two classes of unimolecular reactions can be found in the pyrolysis chemistry of HN-3: pericyclic reactions and initial bond fissions.

The pericyclic reactions that can happen in $\mathrm{HN}-3$ thermal decomposition are presented in reactions (1)-(3). These reactions are similar to those in yperite ${ }^{7}$, but involve nitrogen instead of sulfur.

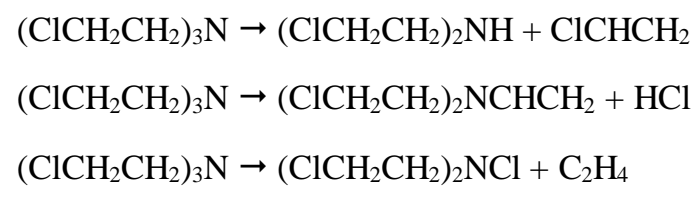

The elementary mechanism of reactions (1) and (3) involves the transfer of $\mathrm{H}$-atom (1) or Clatom (3) from the end of the alkyl chain on the $\mathrm{N}$-atom via a 4-membered ring transition state structure while the $\mathrm{N}-\mathrm{C}$ bond is broken. Reaction (2) is a classical pericyclic elimination of $\mathrm{HCl}$.

The second type of unimolecular reactions in $\mathrm{HN}-3$ are initial bond fissions. The activation energies of these processes are based on bond dissociation energies computed at the CBS-QB3 level of theory (Figure 3). Pre-exponential factors are based on analogies with similar reactions with welldefined kinetic parameters. 


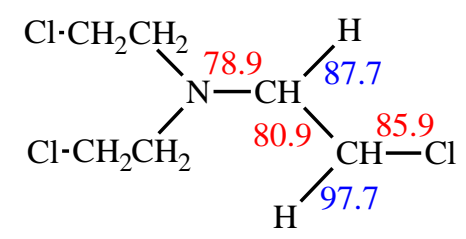

Figure 3. Bond dissociation energies in HN-3 computed at the CBS QB3 level of theory (in kcal mol ${ }^{-1}$ ).

From these values we see that the BDE of the N-C bond is $2 \mathrm{kcal} \mathrm{mol}^{-1}$ lower than the one for the $\mathrm{C}-\mathrm{C}$ bond. Compared to propane, computed value using the CBS-QB3 level of theory, the BDE of the $\mathrm{C}-\mathrm{H}$ bond is lowered by $11.2 \mathrm{kcal} \mathrm{mol}^{-1}$ ( $\mathrm{H}$-atom linked to a secondary carbon) and by $8.3 \mathrm{kcal}$ $\mathrm{mol}^{-1}$ for the $\mathrm{C}-\mathrm{C}$ bond. This effect is mainly due to the presence of the nitrogen atom in the $\beta$ position, whose inductive effects weaken the bonds compared to a normal alkane. The value of the bonding energy of $\mathrm{C}-\mathrm{Cl}$ remains quite close to literature values $\left(84.3 \mathrm{kcal} \mathrm{mol}^{-1}\right.$ after $\mathrm{Luo}^{24}$ in the 1chloropropane).

These values can be compared to those obtained by Wang and $\operatorname{Lin}^{10}$ on triethylamine $\left(\left(\mathrm{CH}_{3} \mathrm{CH}_{2}\right)_{3}-\mathrm{N}\right)$ presented in Figure 2. It can be seen that both results show similar trends for comparable bonds. However, the values computed by Wang and Lin are significantly different in the case of N-C and C-C bonds. The N-C bond dissociation energy, computed value using the CBS-QB3 method (with a reported accuracy of $1.5 \mathrm{kcal} \mathrm{mol}^{-1}$ ), lies $14 \mathrm{kcal} \mathrm{mol}^{-1}$ above the calculated value of Wang and Lin. This can be explained largely by the lower level of calculation used by these authors (B3LYP/6-31G*) which cannot reach accurate absolute energies.

The potential energy surface (PES) of the unimolecular decompositions of HN-3 that were included in the detailed chemical kinetic model are summarized in Figure 4. 


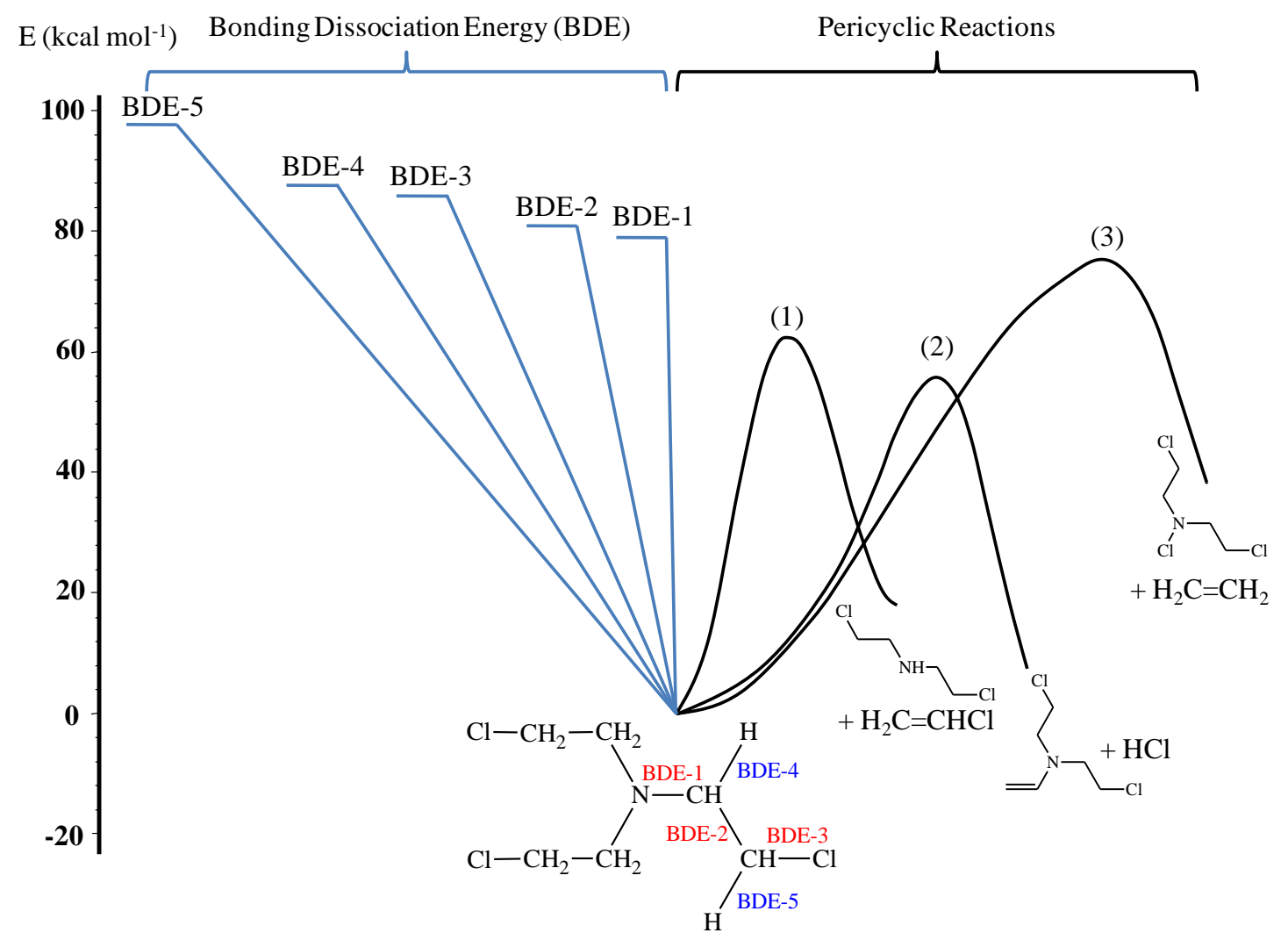

Figure 4. Bond dissociation energies (BDE) and energy barriers of pericyclic reactions in $\mathrm{HN}-3$ computed at the CBS QB3 level of theory (in $\mathrm{kcal} \mathrm{mol}^{-1}$ ).

From Figure 4, it can be observed that the energy barriers of all pericyclic reactions (depicted in Figure 4) lies below the computed bond dissociation energies. $62.4,56.3$ and $75.9 \mathrm{kcal} \mathrm{mol}^{-1}$ at $298 \mathrm{~K}$ for, respectively, the reactions (1), (2) and (3). All the products of these concerted reactions are located above the reactant (endothermic processes). It can be seen that among the pericyclic reactions, reaction (2) is the most favorable with a computed critical energy of $56.3 \mathrm{kcal} \mathrm{mole}^{-1}$.

Reactions (1) and (3) involve a similar mechanism with the only difference being the nature of the atom transferred. In (1) a hydrogen atom is transferred onto the nitrogen atom while in (3) a chlorine atom is transferred. This simple difference strongly impacts the energy barrier as $\mathrm{Cl}$-atom transfer lies $13.5 \mathrm{kcal} \mathrm{mol}^{-1}$ above the critical energy of the process involving the $\mathrm{H}$-atom transfer (75.9 vs $62.4 \mathrm{kcal} \mathrm{mol}^{-1}$ ). The high-pressure limit rate constants calculated for the pericyclic reactions are given in Table $\mathbf{1 .}$

Table 1. High-pressure limit rate constants calculated for pericyclic decompositions in $\mathrm{HN}-3$. Units are $\mathrm{cm}^{3}$, mol, $\mathrm{s}$, cal with $\mathrm{k}=\mathrm{A} \mathrm{T}^{\mathrm{n}} \exp (-\mathrm{E} / \mathrm{RT})$.

\begin{tabular}{ccccc}
\hline Reaction & $\mathrm{A}$ & $\mathrm{n}$ & $\mathrm{E}$ & $\mathrm{k}\left(\mathrm{s}^{-1}, 1000 \mathrm{~K}\right)$ \\
\hline$(1)$ & $4.41 \times 10^{8}$ & 0.717 & 61640 & 0.21 \\
$(2)$ & $1.31 \times 10^{10}$ & 0.387 & 56590 & 81.2 \\
$(3)$ & $9.43 \times 10^{10}$ & 1.256 & 76640 & $9.83 \times 10^{-5}$ \\
\hline
\end{tabular}


From Table 1, it can be seen that $\mathrm{HCl}$ elimination is favored over the other pericyclic reactions (branching ratio $>99 \%$ ).

\section{Bimolecular reactions}

$\mathrm{H}$-abstractions from $\mathrm{HN}-3$ by abundant radicals present in the system $\left(\mathrm{H}, \mathrm{CH}_{3}, \mathrm{CH}_{2} \mathrm{Cl}, \mathrm{NH}_{2}\right.$, $\mathrm{Cl}$ ) were considered in the mechanism. The bimolecular transfer of the chlorine atoms of $\mathrm{HN}-3$ in the abstraction reactions were included only with $\mathrm{H}$ - and $\mathrm{Cl}$-atoms because it has been shown in the literature that these processes are negligible ${ }^{22}$. The high-pressure limit rate constants for the $\mathrm{H}$ abstractions by $\mathrm{H}, \mathrm{CH}_{3}$, and $\mathrm{NH}_{2}$ were calculated using the correlation proposed by Dean and Bozzelli $^{25}$ on the basis of computed enthalpies of reaction determined at the CBS-QB3 level of theory. Kinetic data of the abstractions by $\mathrm{Cl}$-atoms were obtained by analogies with the studies of Karra and Senkan ${ }^{26}$ on the pyrolysis $\mathrm{CH}_{3} \mathrm{Cl}$ and of Bryukov et al. on chloroethane ${ }^{27}$. $\mathrm{H}$-abstractions by $\mathrm{CH}_{2} \mathrm{Cl}$ radicals were directly computed at the CBS-QB3 level of theory. The kinetic parameters of $\mathrm{H}$ abstraction reactions are given in Table $\mathrm{S} 1$.

\section{Unimolecular reactions in the propagations}

The radical formed by $\mathrm{H}$-abstractions from $\mathrm{HN}-3$ can decompose by isomerizations or $\beta$ scissions. Reactions (4) present an example of the possible $\beta$-scission decompositions that can undergo a radical created by an $\mathrm{H}$-abstraction from $\mathrm{HN}-3$.

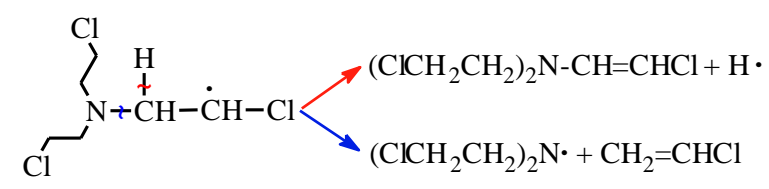

Decomposition reactions by $\beta$-scission of all the radicals have been included in the mechanism. High-pressure limit rate constants of the rupture of N-C, C-C and C-H bonds were calculated at CBSQB3 level of theory for representative radicals (Table 2). In the case of the rupture of the C-Cl bond, which occurs with no saddle point, the pre exponential factor determined experimentally by Knyasev 
et al. ${ }^{28}$ for $\mathrm{H}_{2} \mathrm{C} \cdot-\mathrm{CH}_{2} \mathrm{Cl} \rightarrow \mathrm{H}_{2} \mathrm{C}=\mathrm{CH}_{2}+\mathrm{Cl} \bullet$ was used while the activation energy was set equal to the enthalpy of reaction.

Table 2. High-pressure limit rate constants calculated for $\beta$-scission in $\mathrm{HN}-3$ radicals. Units are $\mathrm{cm}^{3}$, mol, $\mathrm{s}$, cal with $\mathrm{k}=$ A $T^{\mathrm{n}} \exp (-\mathrm{E} / \mathrm{RT})$.

\begin{tabular}{|c|c|c|c|c|}
\hline Reaction & A & $\mathrm{n}$ & $\mathrm{E}$ & $\mathrm{k} 1000 \mathrm{~K}$ \\
\hline$\left(\mathrm{ClCH}_{2} \mathrm{CH}_{2}\right)_{2}-\mathrm{N} \bullet \leftrightarrows \mathrm{ClCH}_{2} \mathrm{CH}_{2}-\mathrm{N}=\mathrm{CHCH}_{2} \mathrm{Cl}+\mathrm{H} \bullet$ & $3.36 \times 10^{11}$ & 0.905 & 33950 & $6.63 \times 10^{6}$ \\
\hline$\left(\mathrm{ClCH}_{2} \mathrm{CH}_{2}\right)_{2}-\mathrm{N} \bullet \leftrightarrows \mathrm{ClCH}_{2} \mathrm{CH}_{2}-\mathrm{N}=\mathrm{CH}_{2}+\bullet \mathrm{CH}_{2} \mathrm{Cl}$ & $3.28 \times 10^{13}$ & 0.292 & 26930 & $3.22 \times 10^{8}$ \\
\hline$\left(\mathrm{ClCH}_{2} \mathrm{CH}_{2}\right)_{2}-\mathrm{N}_{-} \mathrm{CH}_{2} \bullet \leftrightarrows \mathrm{ClCH}_{2} \mathrm{CH}_{2}-\mathrm{N}=\mathrm{CH}_{2}+\bullet \mathrm{CH}_{2} \mathrm{CH}_{2} \mathrm{Cl}$ & $4.35 \times 10^{12}$ & 0.339 & 28620 & $2.53 \times 10^{7}$ \\
\hline$\left(\mathrm{ClCH}_{2} \mathrm{CH}_{2}\right)_{2}-\mathrm{N}_{-} \mathrm{CH}_{2} \mathrm{CH}_{2} \bullet \leftrightarrows\left(\mathrm{ClCH}_{2} \mathrm{CH}_{2}\right)_{2}-\mathrm{N}-\mathrm{CH}=\mathrm{CH}_{2}+\mathrm{H}$ & $7.22 \times 10^{9}$ & 0.981 & 28770 & $3.27 \times 10^{6}$ \\
\hline$\left(\mathrm{ClCH}_{2} \mathrm{CH}_{2}\right)_{2}-\mathrm{N}-\mathrm{CH}_{2} \mathrm{CH}_{2} \bullet \leftrightarrows\left(\mathrm{ClCH}_{2} \mathrm{CH}_{2}\right)_{2}-\mathrm{N} \bullet+\mathrm{CH}_{2}=\mathrm{CH}_{2}$ & $2.76 \times 10^{11}$ & 0.381 & 21550 & $7.47 \times 10^{7}$ \\
\hline$\left(\mathrm{ClCH}_{2} \mathrm{CH}_{2}\right)_{2}-\mathrm{N}-\bullet \mathrm{CHCH}_{2} \mathrm{Cl} \leftrightarrows\left(\mathrm{ClCH}_{2} \mathrm{CH}_{2}\right)_{2}-\mathrm{N}-\mathrm{CH}=\mathrm{CHCl}+\mathrm{H} \bullet$ & $8.78 \times 10^{10}$ & 0.802 & 38280 & $9.63 \times 10^{4}$ \\
\hline$\left(\mathrm{ClCH}_{2} \mathrm{CH}_{2}\right)_{2}-\mathrm{N}-\mathrm{CH}_{2} \mathrm{CHCl} \bullet \leftrightarrows\left(\mathrm{ClCH}_{2} \mathrm{CH}_{2}\right)_{2}-\mathrm{N}-\mathrm{CH}=\mathrm{CHCl}+\mathrm{H} \bullet$ & $1.01 \times 10^{7}$ & 1.764 & 31650 & $2.38 \times 10^{5}$ \\
\hline$\left(\mathrm{ClCH}_{2} \mathrm{CH}_{2}\right)_{2}-\mathrm{N}-\mathrm{CH}_{2} \mathrm{CHCl} \bullet \leftrightarrows\left(\mathrm{ClCH}_{2} \mathrm{CH}_{2}\right)_{2}-\mathrm{N} \bullet+\mathrm{CH}_{2}=\mathrm{CHCl}$ & $2.37 \times 10^{9}$ & 0.865 & 19890 & $4.19 \times 10^{7}$ \\
\hline
\end{tabular}

Isomerization reactions imply an internal $\mathrm{H}$ - or Cl-transfer via a cyclic transition state. By analogy with the hydrocarbons, only isomerizations involving 5- and 6-center TS were considered because they involve lower activation energies than very strained 3- or 4-membered ring TS. For internal $\mathrm{H}$-transfers (excepted for 6 membered ring transition states that were calculated), highpressure limit rate were taken from the correlation defined in $\mathrm{EXGAS}^{19}$, while for the internal Cltransfer the kinetic parameters were calculated at CBS-QB3 level of theory. The associated kinetic parameters can be found in Table S2; Table S3 presents tunneling transmission factors as a function of temperature.

The size and the propensity of HN-3 to form unsaturated intermediates can allow ring closure reactions to occur in the decomposition mechanism. The reaction presented in Table 3 was calculated using quantum chemistry and adopted as a rate rule for 5 membered ring closure in the mechanism when the analogy is possible.

Table 3. High-pressure limit rate constants calculated for the 5-membered ring closure of HN-3 derivatives. Units are $\mathrm{cm}^{3}$, mol, s, cal with $\mathrm{k}=\mathrm{A} \mathrm{T}^{\mathrm{n}} \exp (-\mathrm{E} / \mathrm{RT})$.

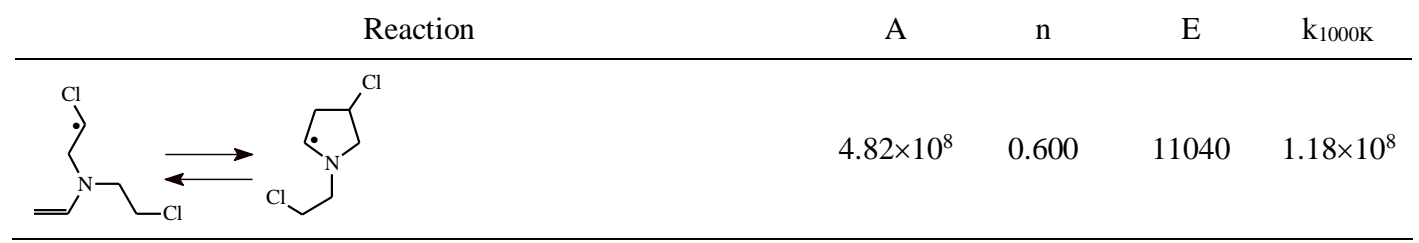

\section{Secondary mechanism}


Once the detailed primary mechanism of $\mathrm{HN}-3$ has been developed, we performed simulations to identify the main primary products. The main primary products formed in the simulations were $\mathrm{P} 2$ $\left(\left(\mathrm{ClCH}_{2} \mathrm{CH}_{2}\right)_{2} \mathrm{~N}-\mathrm{CH}=\mathrm{CH}_{2}\right), \mathrm{P} 4\left(\mathrm{ClCH}_{2} \mathrm{CH}_{2}-\mathrm{N}=\mathrm{CHCH}_{2} \mathrm{Cl}\right)$ and $\mathrm{P} 7\left(\mathrm{ClCH}_{2} \mathrm{CH}_{2}-\mathrm{N}=\mathrm{CH}_{2}\right)$ described in Figure 5.

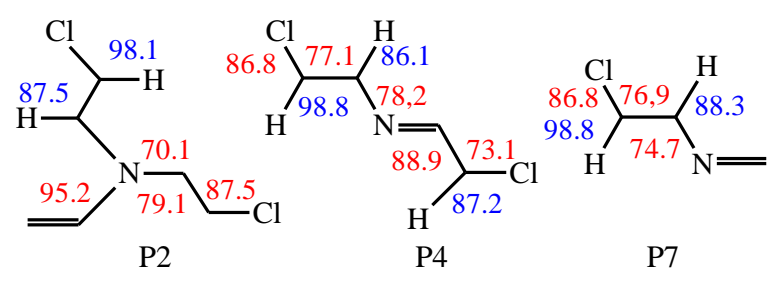

Figure 5. Main products from primary decomposition of HN-3 with their respective bond dissociation energies computed at the CBS-QB3 level of theory (in $\mathrm{kcal} \mathrm{mol}^{-1}$ ).

The P2 species was found with the largest mole fraction among the primary products and is derived mainly from the pericyclic reaction that involves the concerted elimination of $\mathrm{HCl}$ (reaction (2)). P4 and P7 species are formed from $\beta$-scission reactions that can be found in Table 2 in the first and second rows, respectively. The structure of these species shows that they keep similar groups originally present in HN-3. The BDEs of these molecules (displayed in Figure 5) can be compared to those of the reactant and it can be seen that they are close for groups located far from the double bonds. This implies that the pericyclic reactions, unimolecular and bimolecular initiation, and metathesis reactions will be similar to the primary reactions of $\mathrm{HN}-3$ for these groups. It is therefore possible to use, by analogy, the kinetic parameters previously calculated or estimated in the primary mechanism. It is also the case for the radicals created from P2, P4 and P7, for which the kinetic parameters of the $\beta$-scission and isomerization reactions were determined by analogies with those of the primary mechanism.

A particular reaction, the retro-ene molecular reaction, was considered for the P2 species (reaction (5)). The kinetic parameters of this reaction were calculated at the CBS-QB3 level of theory, and were also used for other reactions of the kinetic model involving a similar type of retro-ene mechanism. We can note that this molecular reaction involves sufficiently low activation energy (49 $\mathrm{kcal} \mathrm{mol}^{-1}$ ) to compete with the unimolecular initiation reactions in $\mathrm{P} 2$. 


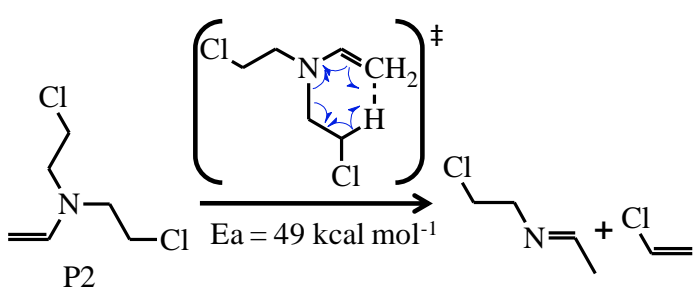

Specific reactions were also added to the $\mathrm{C}_{3}-\mathrm{C}_{4}$ reaction basis of the $\mathrm{C} / \mathrm{H}$ system, which implies a set of decomposition reactions for pyrrole ${ }^{29,30}$ and acetonitrile $\left(\mathrm{CH}_{3} \mathrm{CN}\right)^{31}$ from existing models in the literature. We have also added supplementary reactions to take in account the H-abstractions and addition-elimination reactions of acetonitrile $\mathrm{CH}_{3} \mathrm{CN}$ and also some consumption reactions of radical $\cdot \mathrm{CH}_{2} \mathrm{CN}$, which were not included in the precedent models, these data were obtained by analogy from the similar reactions included in the models described previously (see Table S4).

\section{Results and discussion}

The final pyrolysis kinetic model of tris (2-chloroethyl) amine includes 453 species and 2662 reactions. Simulations for the thermal degradation of HN-3 were performed in an isothermal batch reactor. They were performed under the same conditions as an experimental work on yperite ${ }^{32}$. The aim is, in particular, to determine the kinetics of the toxic thermal degradation and predict the final products formed. These simulations were performed using the SENKIN code (batch reactor model) of the CHEMKIN-II ${ }^{33}$ program suite.

For the pyrolysis simulations, the concentration of $\mathrm{HN}-3$ is set to a mole fraction of $5 \%$ in $95 \%$ of $\mathrm{N}_{2}$. Simulations were also performed with the recently published yperite kinetic model ${ }^{7}$, using the same reactor conditions, to compare the kinetics of thermal decomposition of nitrogen and sulfur mustard gases (Figure 6).

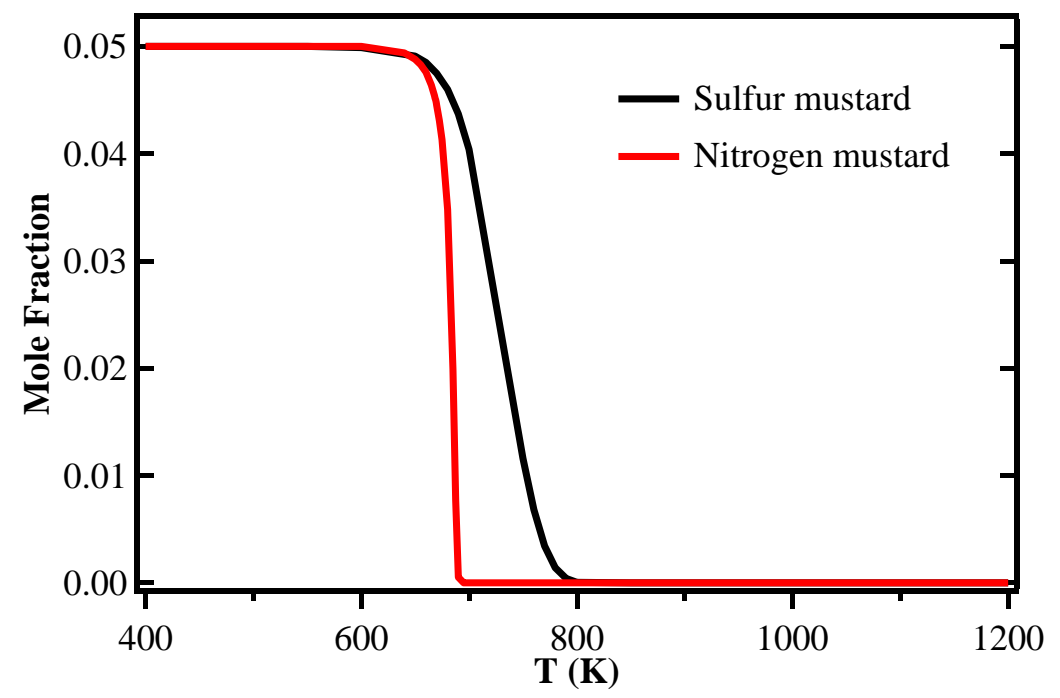


Figure 6. Simulated mole fractions of nitrogen $(\mathrm{HN}-3)$ and sulfur mustard ${ }^{7}$ as a function of temperature during their pyrolysis (conditions: $5 \%$ of toxic in $\mathrm{N}_{2}$ at 0.16 bar and $\mathbf{6 0 0} \mathrm{s}$ residence time). Isochoric and isothermal reactor model.

Figure 6 shows the evolution of the conversion of $\mathrm{HN}-3$ and yperite under pyrolysis conditions, as a function of temperature, for a residence time of $600 \mathrm{~s}$ and an initial pressure of $0.16 \mathrm{bar}$. Under these conditions, it can be seen that the conversion of HN-3 starts around $640 \mathrm{~K}$ and that it is fully consumed at $690 \mathrm{~K}$. Sulfur mustard is shown to be less reactive, even when its degradation starts at the same temperature as the decomposition of $\mathrm{HN} 3$, it is fully consumed at $790 \mathrm{~K}$. As chlorine atoms are the main chain carrier in sulfur mustard ${ }^{7}$ and $\mathrm{HN}-3$ (as shown in the flux analysis detailed later) the most obvious reason for the observed difference in reactivity relies on the higher number of chlorine atoms in $\mathrm{HN}-3$ ( $3 \mathrm{Cl}$-atoms) compared to sulfur mustard (2 Cl-atoms). The flux analysis detailed at the end of this manuscript will also highlights the role of a degenerate chain branching intermediate in the decomposition of $\mathrm{HN}-3$ that increases its reactivity compared to sulfur mustard, where such a mechanism was not observed.

Figure 7 depicts the evolution of the main pyrolysis products as a function of temperature for the same conditions as the one used in Figure 6.

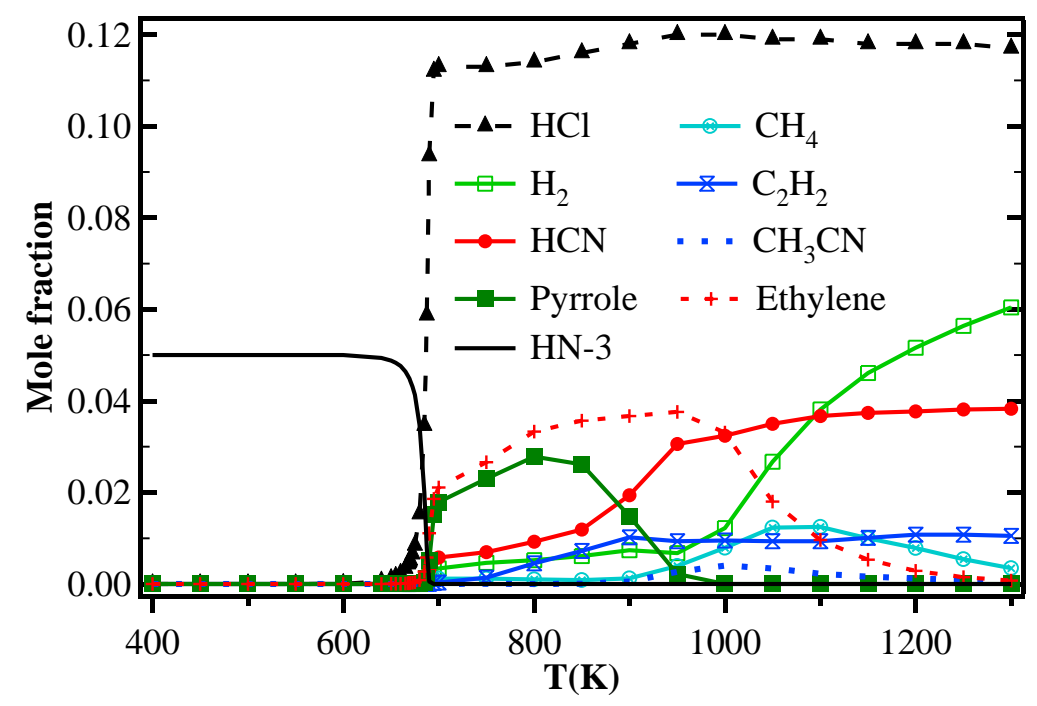

Figure 7. Simulated mole fractions of $\mathrm{HN}-3$ and products as a function of temperature for pyrolysis $\left(5 \%\right.$ of $\mathrm{HN}-3$ in $\left.\mathrm{N}_{2}\right)$ conditions (0.16 bar and $600 \mathrm{~s})$.

It can be seen in Figure 7 that hydrochloric acid $\mathrm{HCl}$ is the main pyrolysis product and that its formation starts at low temperature (around $640 \mathrm{~K}$ ) as soon as the conversion of HN-3 is starting. It will be shown below, in the flux analysis, that this can be explained by the easy Cl-atom loss in HN3 that favors $\mathrm{H}$-abstraction by chlorine from $\mathrm{HN}-3$ and the main primary products. Ethylene is the main hydrocarbon formed at lower temperatures. Acetylene, $\mathrm{H}_{2}$, and highly poisonous hydrogen 
cyanide $(\mathrm{HCN})$ are also formed in important quantities at higher temperatures. At the highest temperature, aromatics are produced in pyrolysis and benzene becomes the main hydrocarbon product. Small yields of acetonitrile $\left(\mathrm{CH}_{3} \mathrm{CN}\right)$ and methane are also predicted in the simulations. It can also be noticed that there is an important formation of pyrrole that starts at $680 \mathrm{~K}$. Its mole fraction reached a maximum around $800 \mathrm{~K}$ and it is fully consumed at $1000 \mathrm{~K}$. The decrease of the pyrrole mole fraction can be partially linked to the increase of $\mathrm{HCN}, \mathrm{C}_{2} \mathrm{H}_{2}, \mathrm{CH}_{3} \mathrm{CN}$ and $\mathrm{CH}_{4}$ mole fractions. Flux analyses presented in Figure 8 gives insights on the elementary chemical processes involves in HN-3 consumption and its pyrolysis products formation routes.

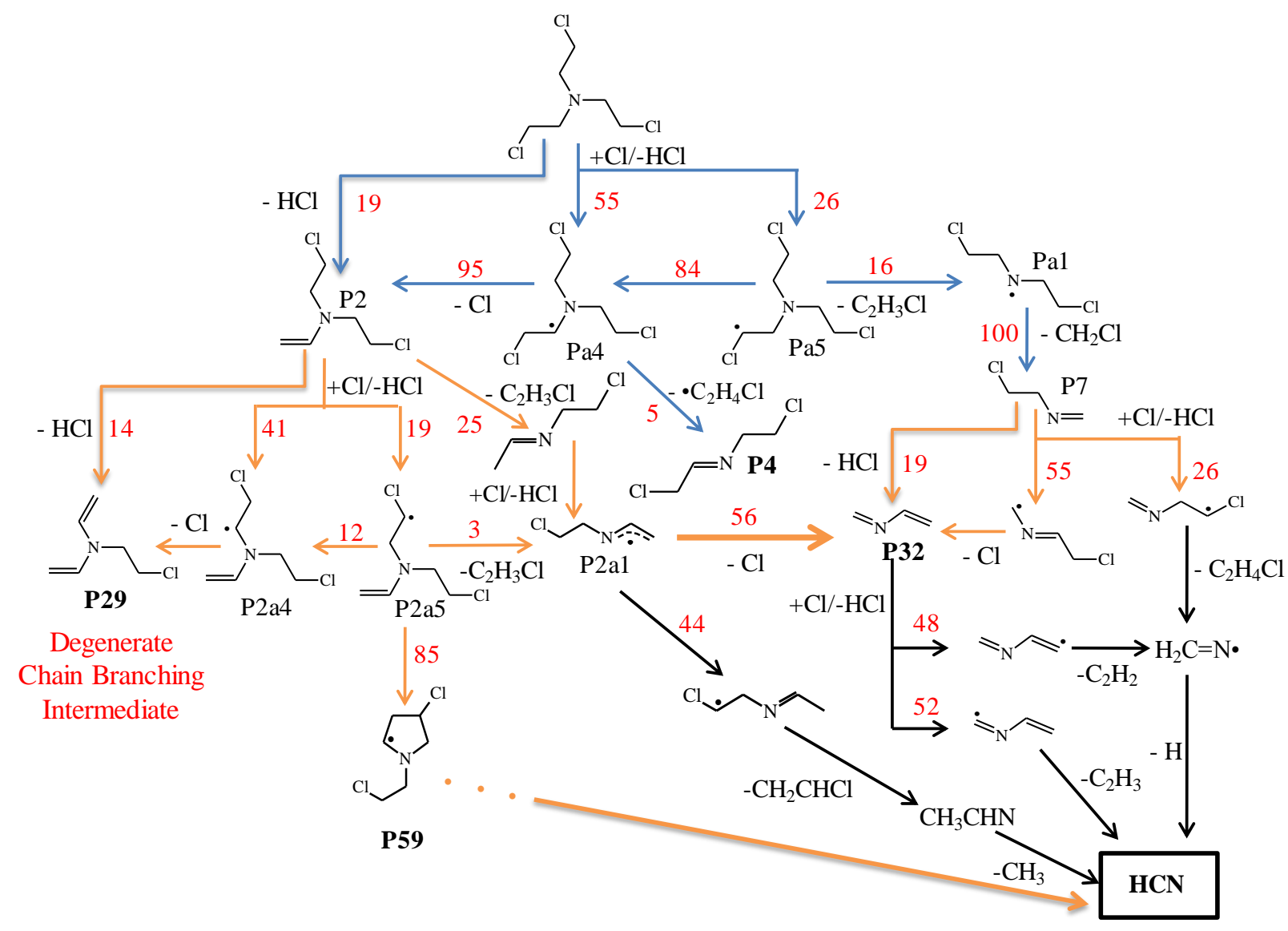

Figure 8. Reaction flux analysis for the pyrolysis of $5 \%$ of $\mathrm{HN}-3$ in $\mathrm{N}_{2}$; conditions: $673 \mathrm{~K}, 0.16$ bar, residence time of $500 \mathrm{~s}$ corresponding to $11 \%$ of $\mathrm{HN}-3$ conversion. Given reaction fluxes are relative to the consumption of a given species and are expressed in percent. 


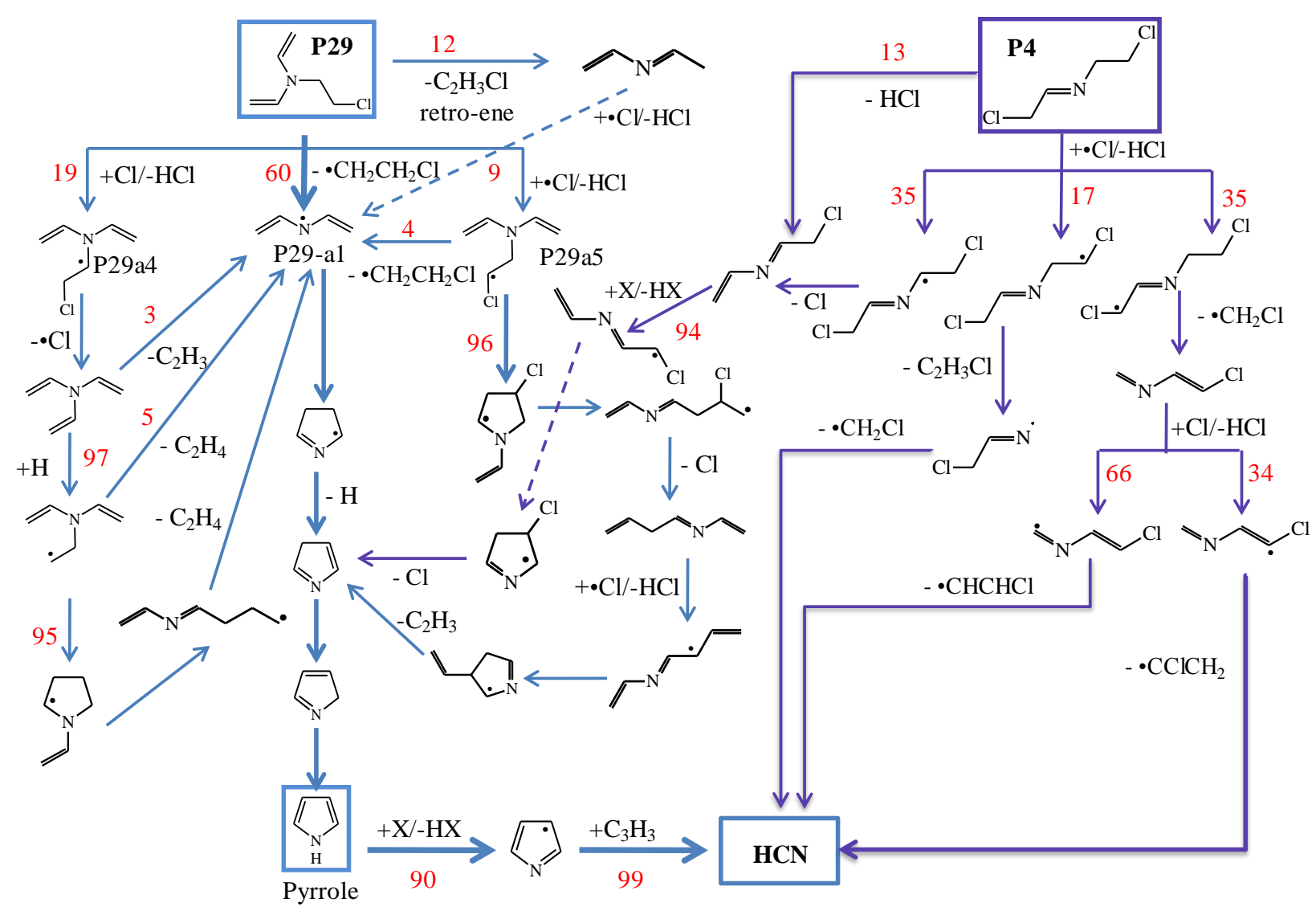

Figure 9. Reaction flux analysis for the pyrolysis of $5 \%$ of $\mathrm{HN}-3$ in $\mathrm{N}_{2}$ related to de decomposition of P29 and P4; conditions: $673 \mathrm{~K}, 0.16$ bar, residence time of 500 s corresponding to $11 \%$ of HN-3 conversion. Given reaction fluxes are relative to the consumption of a given species and are expressed in percent.

At low-temperature $(673 \mathrm{~K})$, the reaction flux analysis (Figure 8) shows that the decomposition of HN-3 is majorly due to $\mathrm{H}$-abstraction by chlorine atoms and that the pericyclic HCl-elimination accounts for $19 \%$ of the total flux of consumption. Simulations show that a small fraction of radical Pa5 decomposes by $\beta$-scission yielding P7 molecule that ultimately decomposes into HCN. Pa5 mainly isomerizes through a 6-centered TS, leading to the formation of Pa4 radical that decomposes into $\mathrm{P} 2$ by $\mathrm{C}-\mathrm{Cl}$ bond $\beta$-scission. This $\beta$-scission is favored by the low activation energy involved ( $\left.25 \mathrm{kcal} \mathrm{mol}^{-1}\right) . \mathrm{H}$-abstraction fluxes majorly lead to the formation of $\mathrm{P} 2$ that decomposes following the same pattern as HN-3, mostly leading to the formation of P29. The main decomposition of P29 is the initial C-N bond fission yielding 1-chloro-ethyl and the stabilized diethenylamino radical P29-a1 (Figure 9). This molecule therefore acts as a chain branching agent as 1-chloro-ethyl decomposes into ethylene and $\mathrm{Cl}$-atom and diethenylamino radical ultimately leads to pyrrole and $\mathrm{H}$-atom. This contributes to the higher reactivity of $\mathrm{HN}-3$ over sulfur mustard gas, where no primary or secondary products noticeably act as a degenerate branching agent. An interesting decomposition route of P2 involves the formation of $\mathrm{P} 2 \mathrm{a} 5$ radical by $\mathrm{H}$-abstraction by $\mathrm{Cl}$-atom that, in turns cyclizes into $\mathrm{P} 59$. 
The decomposition routes of P59 are more complex, but they all ultimately lead to the formation of HCN (see Figure S4). Effect of pressure has been investigated up to 10 bar, without major change in the reaction paths. A higher pressure favors bimolecular reactions, i.e. $\mathrm{H}$-atom abstractions by $\mathrm{Cl}$ atoms, whereas the pericyclic decomposition of nitrogen mustard decreases from $19 \%$ at 0.16 bar to $5 \%$ at 10 bar.

The routes of thermal degradation of HN-3 are characterized by subsequent, stepwise, dechlorination from the reactant and the primary (P2) and secondary (P29) products, predominantly leading to the formation of diethenylamino radical. The fate of diethenylamino radical P29-a1 is therefore central to predict the final pyrolysis products. We performed theoretical calculations to determine the thermal routes of decomposition of this radical and the associated thermo-kinetic parameters. The potential energy surface obtained from our computations at the CBS-QB3 level of theory is presented in Figure 10.

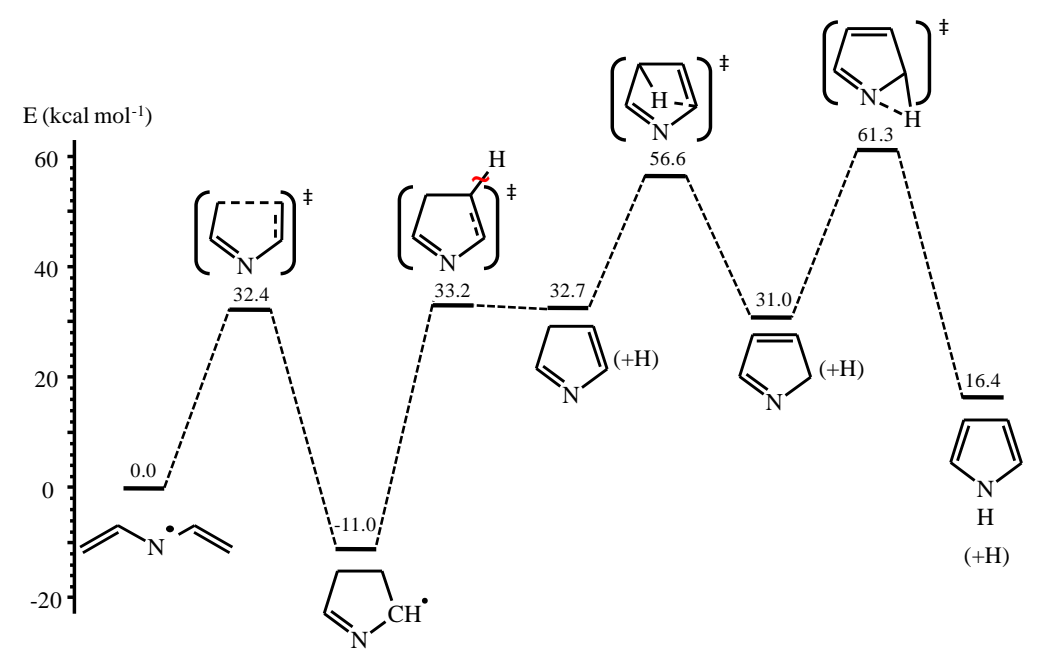

Figure 10. Potential energy surface at $0 \mathrm{~K}$ of diethenylamino radical decomposition computed at the CBS-QB3 level of calculation.

As the $\mathrm{C}-\mathrm{H}$ bond $\beta$-scissions in diethenylamino radical (P29-a1) are unlikely because of the vinylic nature of the $\mathrm{H}$-atoms, its cyclization is the most favored route of degradation. $\mathrm{P} 29$-a1 faces a critical energy of $32.4 \mathrm{kcal} \mathrm{mol}^{-1}$ to form the cyclic, resonant stabilized, radical 3,4-dihydro- $2 \mathrm{H}$ pyrrol-4-yl which is computed to be more stable than diethenylamino radical by $11 \mathrm{kcal} \mathrm{mol}^{-1}$. $\mathrm{H}$ atom loss by $\beta$-scission from this cyclic radical leads to the formation of $3 \mathrm{H}$-pyrrole that can rearrange into pyrrole through subsequent internal $\mathrm{H}$-atom transfers. Thermo-kinetic data calculated from the PES presented in Figure 10 were included in the model and was shown, in the simulation, to be the dominant decomposition pathway of P29-a1 (over bimolecular consumption pathways). 


\section{Conclusion}

The first detailed chemical kinetic model for the pyrolysis of nitrogen mustard gas was developed in this study, based on a large number of theoretical calculations. Based on simulations performed in a batch reactor, it is shown that this toxic molecule is more reactive than sulfur mustard gas. $\mathrm{HCl}$ is predicted to be the main pyrolysis product over a large range of temperature. At lower temperatures, ethylene, pyrrole are the main pyrolysis products while, as temperature increases, $\mathrm{HCN}$, $\mathrm{C}_{2} \mathrm{H}_{2}$ and $\mathrm{H}_{2}$ are predominantly formed because of the decomposition of pyrrole and ethylene. The flux analysis revealed that HN-3 mainly decomposes by stepwise Cl-atom losses, ultimately leading to diethenylamino radical. This radical was shown, by theoretical calculations, to decompose into pyrrole by cyclization coupled to the release of a chlorine atom. Moreover, the P29 specie which leads to the formation of the stabilized diethenylamino radical acts as a degenerate chain branching agent. This represents an important flux of the total consumption of HN-3 ( 52\%) and contributes to explain the highest reactivity of HN-3 over sulfur mustard. Note that the highest number of chlorine atoms in the former structure, and their demonstrated role as principal chain carrier in their thermal decomposition also contributes to explain this predicted higher reactivity.

\section{Acknowledgements}

This work was supported by DGA Maîtrise NRBC. This work was granted access to the HPC resources of CINES under the allocation 2015087249 made by GENCI.

\section{Supporting Information}

In supplemental are provided the rate constants of $\mathrm{H}$-atom abstractions from $\mathrm{HN}-3$, of internal $\mathrm{H}$ transfer reactions in $\mathrm{HN}-3$ radicals, and of the additional set of reactions for $\mathrm{CH} 3 \mathrm{CN}$, and the reaction flux analysis for P59 intermediate in the condition of figure 8. This material is available free of charge via the Internet at http://pubs.acs.org

\section{References}

(1) Gresham, G. L.; Groenewold, G. S.; Olson, J. E. Identification of the Nitrogen-Based Blister Agents Bis (2-Chloroethyl) Methylamine (HN-2) and Tris (2-Chloroethyl) Amine (HN-3) and Their Hydrolysis Products on Soil Using Ion Trap Secondary Ion Mass Spectrometry. J. Mass Spectrom. 2000, 35 (12), 1460-1469. 
(2) CDC - The Emergency Response Safety and Health Database: Blister Agent: NITROGEN MUSTARD $\mathrm{HN}-3$

https://www.cdc.gov/niosh/ershdb/emergencyresponsecard_29750012.html (accessed Feb 1, 2017).

(3) Kanu, A. B.; Haigh, P. E.; Hill, H. H. Surface Detection of Chemical Warfare Agent Simulants and Degradation Products. Anal. Chim. Acta 2005, 553 (1), 148-159.

(4) Pearson, G. S.; Magee, R. S. Critical Evaluation of Proven Chemical Weapon Destruction Technologies (IUPAC Technical Report). Pure Appl. Chem. 2002, 74 (2), 187-316.

(5) Munro, N. B.; Talmage, S. S.; Griffin, G. D.; Waters, L. C.; Watson, A. P.; King, J. F.; Hauschild, V. The Sources, Fate, and Toxicity of Chemical Warfare Agent Degradation Products. Environ. Health Perspect. 1999, 107 (12), 933-974.

(6) Chatterji, D. C. Potential Errors in Kinetic Studies of Hydrolysis of Nitrogen Mustards Based on Chloride-Ion Determination. J. Pharm. Sci. 1980, 69 (7), 859-861.

(7) Sirjean, B.; Lizardo-Huerta, J.-C.; Verdier, L.; Fournet, R.; Glaude, P.-A. Kinetic Modeling of the Thermal Destruction of Mustard Gas. Proc. Combust. Inst. 2017, 36 (1), 499-506.

(8) Cullis, C. F.; Waddington, D. J. The Gaseous Oxidation of Tertiary Aliphatic Amines. I. Triethylamine. In Proceedings of the Royal Society of London A: Mathematical, Physical and Engineering Sciences; The Royal Society, 1958; Vol. 244, pp 110-123.

(9) Wang, Z.; Lin, R.; Fang, W.; Li, G.; Guo, Y.; Qin, Z. Triethylamine as an Initiator for Cracking of Heptane. Energy 2006, 31 (14), 2773-2790.

(10) Wang, Z.; Lin, R. Theoretical Study on the Reaction Route for the Major Liquid Product from Pyrolysis of Triethylamine. J. Anal. Appl. Pyrolysis 2008, 81 (2), 205-210.

(11) Montgomery, J.; Frisch, M. J.; Ochterski, J. W.; Petersson, G. A. A Complete Basis Set Model Chemistry. VI. Use of Density Functional Geometries and Frequencies. J. Chem. Phys. 1999, $110(6), 2822-2827$.

(12) Montgomery Jr, J. A.; Frisch, M. J.; Ochterski, J. W.; Petersson, G. A. A Complete Basis Set Model Chemistry. VII. Use of the Minimum Population Localization Method. J. Chem. Phys. 2000, 112 (15), 6532-6542.

(13) Malick, D. K.; Petersson, G. A.; Montgomery Jr, J. A. Transition States for Chemical Reactions I. Geometry and Classical Barrier Height. J. Chem. Phys. 1998, 108 (14), 5704-5713.

(14) Frisch, M.; Trucks, G.; Schlegel, H.; Scuseria, G.; Robb, M.; Cheeseman, J.; Scalmani, G.; Barone, V.; Mennucci, B.; Petersson, G.; et al. Gaussian 09 Revision C.01.

(15) Lizardo-Huerta, J. C.; Sirjean, B.; Bounaceur, R.; Fournet, R. Intramolecular Effects on the Kinetics of Unimolecular Reactions of $\beta$-HOROO and HOQ ${ }^{\circ} \mathrm{OOH}$ Radicals. Phys. Chem. Chem. Phys. 2016, 18 (17), 12231-12251.

(16) Vansteenkiste, P.; Van Neck, D.; Van Speybroeck, V.; Waroquier, M. An Extended HinderedRotor Model with Incorporation of Coriolis and Vibrational-Rotational Coupling for Calculating Partition Functions and Derived Quantities. J. Chem. Phys. 2006, 124 (4), 044314.

(17) Miyoshi. BEx1D software, rev. 2012.03.12, available from the author. http://akrmys.com/bex1d/.

(18) Eckart, C. The Penetration of a Potential Barrier by Electrons. Phys. Rev. 1930, 35 (11), 1303.

(19) Buda, F.; Bounaceur, R.; Warth, V.; Glaude, P. A.; Fournet, R.; Battin-Leclerc, F. Progress toward a Unified Detailed Kinetic Model for the Autoignition of Alkanes from C4 to C10 between 600 and 1200 K. Combust. Flame 2005, 142 (1-2), 170-186.

(20) Fournet, R.; Bauge, J. C.; Battin-Leclerc, F. Experimental and Modeling of Oxidation of Acetylene, Propyne, Allene and 1,3-Butadiene. Int. J. Chem. Kinet. 1999, 31 (5), 361-379.

(21) Pousse, E.; Glaude, P. A.; Fournet, R.; Battin-Leclerc, F. A Lean Methane Premixed Laminar Flame Doped with Components of Diesel Fuel:: I. N-Butylbenzene. Combust. Flame 2009, 156 (5), 954-974. 
(22) Leylegian, J. C.; Zhu, D. L.; Law, C. K.; Wang, H. Experiments and Numerical Simulation on the Laminar Flame Speeds of Dichloromethane and Trichloromethane. Combust. Flame 1998, 114 (3), 285-293.

(23) Konnov, A. A.; Barnes, F. J.; Bromly, J. H.; Zhu, J. N.; Zhang, D. The Pseudo-Catalytic Promotion of Nitric Oxide Oxidation by Ethane at Low Temperatures. Combust. Flame 2005, 141 (3), 191-199.

(24) Luo, Y. R. Handbook of Bond Dissociation Energies in Organic Compounds; CRC Press: Boca Raton, 2003.

(25) Dean, A. M.; Bozzelli, J. W. Combustion Chemistry of Nitrogen. In Gas-phase combustion chemistry; Springer, 2000; pp 125-341.

(26) Karra, S. B.; Senkan, S. M. A Detailed Chemical Kinetic Mechanism for the Oxidative Pyrolysis of Chloromethane. Ind. Eng. Chem. Res. 1988, 27 (7), 1163-1168.

(27) Bryukov, M. G.; Slagle, I. R.; Knyazev, V. D. Kinetics of Reactions of Cl Atoms with Ethane, Chloroethane, and 1, 1-Dichloroethane. J. Phys. Chem. A 2003, 107 (34), 6565-6573.

(28) Knyazev, V. D.; Kalinovski, I. J.; Slagle, I. R. Kinetics of the $\mathrm{CH} 2 \mathrm{CH} 2 \mathrm{Cl} \rightleftarrows \mathrm{C} 2 \mathrm{H} 4+\mathrm{Cl}$ Reaction. J. Phys. Chem. A 1999, 103 (17), 3216-3221.

(29) Lumbreras, M.; Alzueta, M. U.; Millera, A.; Bilbao, R. A Study of Pyrrole Oxidation under Flow Reactor Conditions. Combust. Sci. Technol. 2001, 172 (1), 123-139.

(30) Lifshitz, A.; Tamburu, C.; Suslensky, A. Isomerization and Decomposition of Pyrrole at Elevated Temperatures: Studies with a Single-Pulse Shock Tube. J. Phys. Chem. 1989, 93 (15), 5802-5808.

(31) Lifshitz, A.; Tamburu, C. Thermal Decomposition of Acetonitrile. Kinetic Modeling. Int. J. Chem. Kinet. 1998, 30 (5), 341-347.

(32) Battin-Leclerc, F.; Baronnet, F.; Paternotte, G.; Leclerc, J. P.; Gourhan, R. Thermal Decomposition of Chloropicrin, Diphosgene and Phosgene between 100 and $530^{\circ} \mathrm{C}$. J. Anal. Appl. Pyrolysis 2000, 53 (1), 95-105.

(33) Kee, R. J.; Rupley, F. M.; Miller, J. A. CHEMKIN-II: A FORTRAN Chemical Kinetics Package for the Analysis of Gas-Phase Chemical Kinetics. Sandia Laboratories Report, S 89-8009B 1993. 


\section{Supplemental Material}

\section{Kinetic modeling of the thermal destruction of nitrogen mustard gas}

\section{Juan-Carlos Lizardo-Huertal, Baptiste Sirjean ${ }^{1}$, Laurent Verdier ${ }^{2}$, René} Fournet $^{l}$, Pierre-Alexandre Glaude ${ }^{l}$

${ }^{1}$ Laboratoire Réactions et Génie des Procédés, CNRS, Université de Lorraine, 1 rue Grandville BP 2045154001 Nancy Cedex, France

${ }^{2}$ DGA Maîtrise NRBC, Site du Bouchet, 5 rue Lavoisier, BP $n^{\circ}$ 3, 91710 Vert le Petit, France

- Table S1: High-pressure limit rate constants for the H-abstraction reactions in HN-3.

- Table S2: High-pressure limit rate constants for the internal H-transfers reactions in $\mathrm{HN}-3$ radicals.

- Table S3: Tunneling effect (Eckart 1-D) for some internal H-transfer reactions.

- Table S4: High-pressure limit rate constants for the supplementary reactions to take in account the $\mathrm{H}$-abstractions and addition-elimination of $\mathrm{CH}_{3} \mathrm{CN}$ and consumption reactions of $\bullet \mathrm{CH}_{2} \mathrm{CN}$.

- Figure S4: Reaction flux analysis for the pyrolysis of $5 \%$ of $\mathrm{HN}-3$ in $\mathrm{N}_{2}$ related to the decomposition of the P59 radical; conditions: $673 \mathrm{~K}, 0.16$ bar, residence time of $500 \mathrm{~s}$ corresponding to $11 \%$ of $\mathrm{HN}-3$ conversion. 
Table S1: High-pressure limit rate constants for the $\mathrm{H}$-abstraction reactions in $\mathrm{HN}-3$. $k=A T^{n} \exp (-E / R T)$, in $\mathrm{cm}^{3}$, mol, $s$, cal.

\begin{tabular}{lcccc}
\hline \multicolumn{1}{c}{ Reaction } & A & n & E & Ref. \\
\hline $\mathrm{HN}-3+\mathrm{H} \leftrightarrows(\mathrm{ClCH} 2 \mathrm{CH} 2) 2 \mathrm{NC} \cdot \mathrm{HCH} 2 \mathrm{Cl}+\mathrm{H} 2$ & $1.44 \times 10^{9}$ & 1.5 & -2060 & {$[1]$} \\
$\mathrm{HN}-3+\mathrm{H} \leftrightarrows(\mathrm{ClCH} 2 \mathrm{CH} 2) 2 \mathrm{NCH} 2 \mathrm{C} \cdot \mathrm{HCl}+\mathrm{H} 2$ & $1.44 \times 10^{9}$ & 1.5 & 4456 & {$[1]$} \\
$\mathrm{HN}-3+\mathrm{H} \leftrightarrows(\mathrm{ClCH} 2 \mathrm{CH} 2) 2 \mathrm{NCH} 2 \mathrm{CH} 2 \bullet+\mathrm{HCl}$ & $9.47 \times 10^{13}$ & 0.0 & 8600 & {$[2]$} \\
\hline $\mathrm{HN}-3+\mathrm{Cl} \leftrightarrows(\mathrm{ClCH} 2 \mathrm{CH} 2) 2 \mathrm{NC} \cdot \mathrm{HCH} 2 \mathrm{Cl}+\mathrm{HCl}$ & $5.90 \times 10^{13}$ & 0.0 & 179 & {$[3]$} \\
$\mathrm{HN}-3+\mathrm{Cl} \leftrightarrows(\mathrm{ClCH} 2 \mathrm{CH} 2) 2 \mathrm{NCH} 2 \mathrm{C} \cdot \mathrm{HCl}+\mathrm{HCl}$ & $4.98 \times 10^{13}$ & 0.0 & 904 & {$[4]$} \\
$\mathrm{HN}-3+\mathrm{Cl} \leftrightarrows(\mathrm{ClCH} 2 \mathrm{CH} 2) 2 \mathrm{NCH} 2 \mathrm{CH} 2 \bullet+\mathrm{Cl} 2$ & $1.28 \times 10^{13}$ & 0.0 & 27000 & {$[5]$} \\
\hline $\mathrm{HN}-3+\mathrm{CH} 3 \leftrightarrows(\mathrm{ClCH} 2 \mathrm{CH} 2) 2 \mathrm{NC} \cdot \mathrm{HCH} 2 \mathrm{Cl}+\mathrm{CH} 4$ & $4.86 \times 10^{6}$ & 1.9 & 1501 & {$[1]$} \\
$\mathrm{HN}-3+\mathrm{CH} 3 \leftrightarrows(\mathrm{ClCH} 2 \mathrm{CH} 2) 2 \mathrm{NCH} 2 \mathrm{C} \cdot \mathrm{HCl}+\mathrm{CH} 4$ & $4.86 \times 10^{6}$ & 1.9 & 8018 & {$[1]$} \\
\hline $\mathrm{HN}-3+\mathrm{CH} 2 \mathrm{Cl} \leftrightarrows(\mathrm{ClCH} 2 \mathrm{CH} 2) 2 \mathrm{NC} \cdot \mathrm{HCH} 2 \mathrm{Cl}+$ & $7.40 \times 10^{0}$ & 3.4 & 7915 & $\mathrm{CBS}-\mathrm{QB} 3$ \\
$\mathrm{CH} 3 \mathrm{Cl}$ & & & & \\
$\mathrm{HN}-3+\mathrm{CH} 2 \mathrm{Cl} \leftrightarrows(\mathrm{ClCH} 2 \mathrm{CH} 2) 2 \mathrm{NCH} 2 \mathrm{C} \cdot \mathrm{HCl}+$ & $1.55 \times 10^{0}$ & 3.4 & 8301 & $\mathrm{CBS}-\mathrm{QB} 3$ \\
$\mathrm{CH} 3 \mathrm{Cl}$ & & & & {$[1]$} \\
\hline $\mathrm{HN}-3+\mathrm{NH} 2 \leftrightarrows(\mathrm{ClCH} 2 \mathrm{CH} 2) 2 \mathrm{NC} \cdot \mathrm{HCH} 2 \mathrm{Cl}+\mathrm{NH} 3$ & $5.52 \times 10^{10}$ & 1.9 & 4337 & {$[1]$} \\
$\mathrm{HN}-3+\mathrm{NH} 2 \leftrightarrows(\mathrm{ClCH} 2 \mathrm{CH} 2) 2 \mathrm{NCH} 2 \mathrm{C} \bullet \mathrm{HCl}+\mathrm{NH} 3$ & $5.52 \times 10^{10}$ & 1.9 & 6643 & \\
\hline
\end{tabular}


Table S2: High-pressure limit rate constants for the internal $H$-transfers reactions in $\mathrm{HN}-3$ radicals. $\mathrm{k}=\mathrm{A} \mathrm{T}^{\mathrm{n}} \exp (-\mathrm{E} / \mathrm{RT})$, in $\mathrm{cm}^{3}$, mol, $\mathrm{s}$, cal.

\begin{tabular}{|c|c|c|c|c|}
\hline Reaction & A & $\mathrm{n}$ & $\mathrm{E}$ & Ref. \\
\hline$\left(\mathrm{ClCH}_{2} \mathrm{CH}_{2}\right)_{2}-\mathrm{N}-\mathrm{CH}_{2} \mathrm{CH}_{2} \bullet \leftrightarrows \mathrm{ClCH}_{2} \mathrm{CH}_{2}-\mathrm{N}-\left(\mathrm{CH}_{2} \mathrm{CH}_{3}\right)\left(\mathrm{CH}_{2} \mathrm{CHCl} \bullet\right)$ & $1.98 \times 10^{8}$ & 1.000 & 12000 & [6] \\
\hline$\left(\mathrm{ClCH}_{2} \mathrm{CH}_{2}\right)_{2}-\mathrm{N}_{-}-\mathrm{CH}_{2} \mathrm{CH}_{2} \bullet \leftrightarrows \mathrm{ClCH}_{2} \mathrm{CH}_{2}-\mathrm{N}-\left(\mathrm{CH}_{2} \mathrm{CH}_{3}\right)\left(\mathrm{CH} \cdot \mathrm{CH}_{2} \mathrm{Cl}\right)$ & $1.15 \times 10^{9}$ & 1.000 & 17300 & [6] \\
\hline$\left(\mathrm{ClCH}_{2} \mathrm{CH}_{2}\right)_{2}-\mathrm{N}-\mathrm{CH}_{2} \bullet \leftrightarrows \mathrm{ClCH}_{2} \mathrm{CH}_{2}-\mathrm{N}-\left(\mathrm{CH}_{3}\right)\left(\mathrm{CH}_{2} \mathrm{CHCl} \bullet\right)$ & $1.15 \times 10^{9}$ & 1.000 & 17300 & [6] \\
\hline$\left(\mathrm{ClCH}_{2} \mathrm{CH}_{2}\right)_{2}-\mathrm{N} \bullet \leftrightarrows \mathrm{ClCH}_{2} \mathrm{CH}_{2}-\mathrm{NH}-\left(\mathrm{CH}_{2} \mathrm{CHCl} \bullet\right)$ & $6.69 \times 10^{9}$ & 1.000 & 37000 & [6] \\
\hline $\mathrm{ClCH}_{2} \mathrm{CH}_{2}-\mathrm{N}-\left(\mathrm{CH}_{2} \mathrm{CH}_{3}\right)\left(\mathrm{CH}_{2} \mathrm{CHCl} \bullet\right) \leftrightarrows\left(\mathrm{ClCH}_{2} \mathrm{CH}_{2}\right)_{2}-\mathrm{N}-\mathrm{CH} \cdot \mathrm{CH}_{2}$ & $5.75 \times 10^{8}$ & 1.000 & 17300 & [6] \\
\hline $\mathrm{ClCH}_{2} \mathrm{CH}_{2}-\mathrm{N}-\left(\mathrm{CH}_{2} \mathrm{CH}_{3}\right)\left(\mathrm{CH}_{2} \mathrm{CHCl} \bullet\right) \leftrightarrows \mathrm{ClCH}_{2} \mathrm{CH}_{2}-\mathrm{N}-\left(\mathrm{CH}_{2} \mathrm{CH}_{3}\right)\left(\mathrm{CH} \cdot \mathrm{CH}_{2} \mathrm{Cl}\right)$ & $5.75 \times 10^{8}$ & 1.000 & 17300 & [6] \\
\hline$\left(\mathrm{ClCH}_{2} \mathrm{CH}_{2}\right)_{2}-\mathrm{N}-\mathrm{CH}_{2} \bullet \leftrightarrows \mathrm{ClCH}_{2} \mathrm{CH}_{2}-\mathrm{N}-\left(\mathrm{CH}_{2} \mathrm{Cl}\right)\left(\mathrm{CH}_{2} \mathrm{CH}_{2} \bullet\right)$ & $1.15 \times 10^{9}$ & 1.000 & 17300 & [6] \\
\hline$\left(\mathrm{ClCH}_{2} \mathrm{CH}_{2}\right)_{2}-\mathrm{N}-\mathrm{CH}_{2} \bullet \leftrightarrows \mathrm{ClCH}_{2} \mathrm{CH}_{2}-\mathrm{N}-\left(\mathrm{CH}_{2} \mathrm{Cl}\right)\left(\mathrm{CH}_{2} \mathrm{CH}_{2} \bullet\right)$ & $5.30 \times 10^{10}$ & 0,511 & 29252 & CBS-QB3 \\
\hline
\end{tabular}


Table S3: Tunneling effect (Eckart 1-D) for some internal H-transfer reactions.

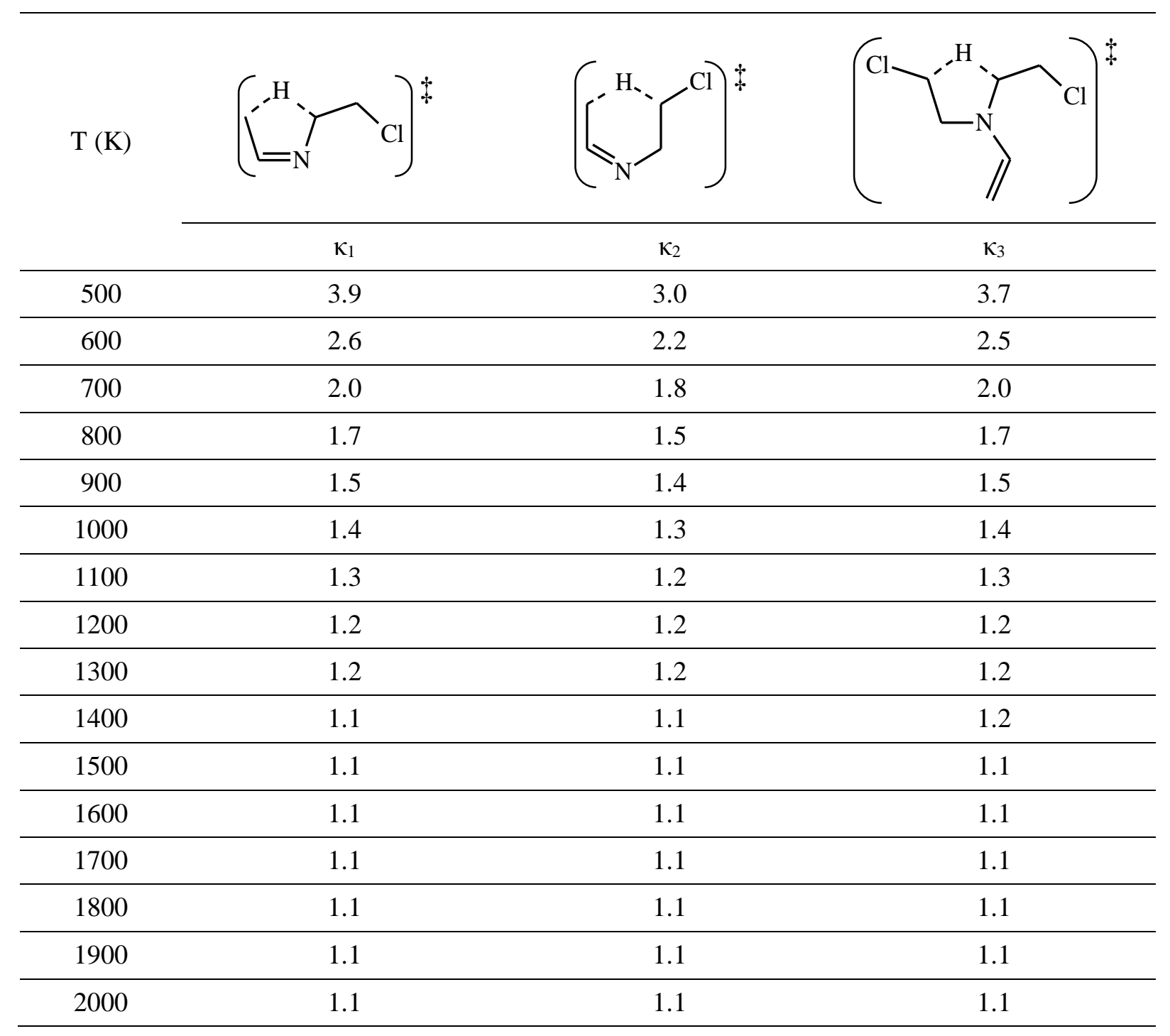


Table S4: High-pressure limit rate constants for the supplementary reactions to take in account the $\mathrm{H}$-abstractions and addition-elimination of $\mathrm{CH}_{3} \mathrm{CN}$ and consumption reactions of $\bullet \mathrm{CH}_{2} \mathrm{CN} . \mathrm{k}=\mathrm{A} \mathrm{T}^{\mathrm{n}} \exp (-\mathrm{E} / \mathrm{RT})$, in $\mathrm{cm}^{3}, \mathrm{~mol}, \mathrm{~s}$, cal.

\begin{tabular}{lllll}
\hline \multicolumn{1}{c}{ Reaction } & $\mathrm{A}$ & $\mathrm{n}$ & $\mathrm{E}$ & Ref. \\
\hline $\mathrm{CH}_{3} \mathrm{CN}$ & & & & \\
\hline 1. $\mathrm{CH}_{3} \mathrm{CN}+\mathrm{Cl}=\mathrm{CH}_{2} \mathrm{CN}+\mathrm{HCl}$ & $9.64 \times 10^{12}$ & 0.0 & 4253 & {$[7]$} \\
\hline 2. $\mathrm{CH}_{3} \mathrm{CN}+\mathrm{O}=\mathrm{CH}_{2} \mathrm{CN}+\mathrm{OH}$ & $4.73 \times 10^{8}$ & 1.8 & 14400 & {$[8]$} \\
\hline 3. $\mathrm{CH}_{3} \mathrm{CN}+\mathrm{OH}=\mathrm{CH} 2 \mathrm{CN}+\mathrm{H}_{2} \mathrm{O}$ & $2.63 \times 10^{5}$ & 2.49 & 4207 & {$[9]$} \\
\hline 4. $\mathrm{CH}_{3} \mathrm{CN}+\mathrm{O}=\mathrm{NCO}+\mathrm{CH}$ & $2.88 \times 10^{9}$ & 1.27 & 17710 & {$[8]$} \\
\hline 5. $\mathrm{CH}_{3} \mathrm{CN}+\mathrm{N}=\mathrm{HCN}+\mathrm{HCN}+\mathrm{H}$ & $1.37 \times 10^{9}$ & 0.0 & 1616 & {$[10]$} \\
\hline - $\mathrm{CH}_{2} \mathrm{CN}$ & & & & \\
\hline 1. $\mathrm{CH}_{2} \mathrm{CN}+\mathrm{O}=\mathrm{HCHO}+\mathrm{CN}$ & $1.00 \times 10^{13}$ & 0.0 & 0 & {$[6]$} \\
\hline 2. $\mathrm{CH}_{2} \mathrm{CN}+\mathrm{OOH}=\mathrm{HCHO}+\mathrm{CN}+\mathrm{OH}$ & $5.00 \times 10^{12}$ & 0.0 & 0 & {$[6]$} \\
\hline 3. $\mathrm{CH}_{2} \mathrm{CNH}+\mathrm{O}=\mathrm{HCHO}+\mathrm{HCN}$ & $1.00 \times 10^{13}$ & 0.0 & 0 & {$[6]$} \\
\hline 4. $\mathrm{CH}_{2} \mathrm{CNH}+\mathrm{OH}=\mathrm{HCHO}+\mathrm{HCNH}$ & $5.00 \times 10^{12}$ & 0.0 & 0 & {$[6]$} \\
\hline 5. $\mathrm{CH}_{2}+\mathrm{CN}=\mathrm{CH}{ }_{2} \mathrm{CN}$ & $5.00 \times 10^{12}$ & 0.0 & 0 & {$[6]$} \\
\hline
\end{tabular}




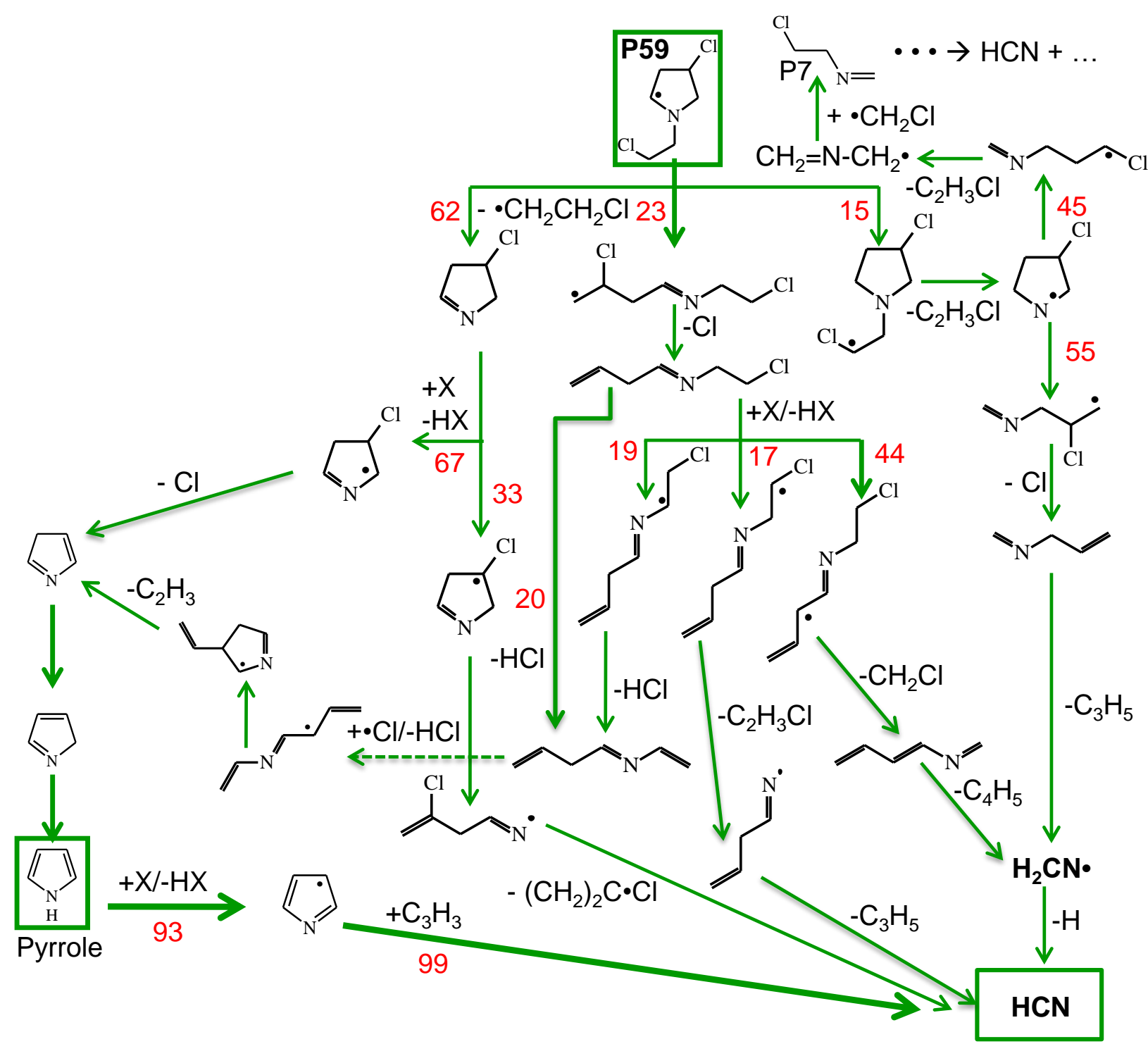

Figure S4. Reaction flux analysis for the pyrolysis of $5 \%$ of $\mathrm{HN}-3$ in $\mathrm{N}_{2}$ related to the decomposition of the $P 59$ radical; conditions: $673 \mathrm{~K}, 0.16$ bar, residence time of $500 \mathrm{~s}$ corresponding to $11 \%$ of $\mathrm{HN}-3$ conversion. Given reaction fluxes are relative to the consumption of a given species and are expressed in percent. 


\section{References}

[1] Dean, A.M., Bozzelli, J.W., Combustion Chemistry of Nitrogen, in Gas-Phase Combustion Chemistry, W. C. Gardiner, Jr., Springer New York, Inc., 2000.

[2] Karra, S.B., Senkan, S.M., A detailed chemical kinetic mechanism for the oxidative pyrolysis of chloromethane. Ind. Eng. Chem. Res. 1988, 27, 1163-1168.

[3] Pilgrim, J.S., Taatjes, C.A., Infrared Absorption Probing of the $\mathrm{Cl}+\mathrm{C} 3 \mathrm{H} 6$ Reaction: Rate Coefficients for $\mathrm{HCl}$ Production between 290 and 800 K. J. Phys. Chem. A 1997, 101, $5776-5782$.

[4] Bryukov, M.G., Slagle, I.R., Knyazev, V.D., Kinetics of Reactions of Cl Atoms with Ethane, Chloroethane, and 1,1-Dichloroethane. J. Phys. Chem. A 2003, 107, 6565-6573.

[5] Bell, T.N., Perkins, K., Perkins, P.G., The chlorination of paraffin hydrocarbons. Calculation of the activation energies and A factors for reactions in the total chlorination of methane. J. Phys. Chem. 1977, 81, 2610-2614.

[6] Buda, F., Bounaceur, R., Warth, V., Glaude, P.A., et al., Progress toward a unified detailed kinetic model for the autoignition of alkanes from $\mathrm{C} 4$ to $\mathrm{C} 10$ between 600 and 1200 K. Combust. Flame 2005, 142, 170-186.

[7] Tyndall, G.S., Orlando, J.J., Wallington, T.J., Sehested, J., et al., Kinetics of the Reactions of Acetonitrile with Chlorine and Fluorine Atoms. J. Phys. Chem. 1996, 100, 660-668.

[8] Sun, J., Tang, Y., Jia, X., Wang, F., et al., Theoretical study for the reaction of CH3CN with O(P3). J. Chem. Phys. 2010, 132, 064301.

[9] Li, Q.-S., Wang, C.Y., Direct dynamic study on the hydrogen abstraction reaction $\mathrm{CH} 3 \mathrm{CN}+\mathrm{OH} \rightarrow \mathrm{CH} 2 \mathrm{CN}+\mathrm{H} 2 \mathrm{O}$. J. Comput. Chem. 2004, 25, 251-257.

[10] Forst, W., Evans, H.G.V., Winkler, C.A., The Kinetics of Nitrogen Atom Reactions Accompanied by Catalyzed Recombination of Atoms. J. Phys. Chem. 1957, 61, 320-325. 